\title{
Theoretical study on the Rh-catalyzed C-C activation of cyclopropanol to construct diketone or monoketone
}

\author{
Tao Liu ${ }^{1}$, Ping Wang ${ }^{2}$, and Hong Ren ${ }^{1}$ \\ ${ }^{1}$ Jining University \\ ${ }^{2}$ Qufu Normal University
}

June 8, 2020

\begin{abstract}
The mechanisms of C-C activation of 1-Benzylcyclopropan-1-ol to produce 1,6-diketone have been investigated by density functional theory (DFT) calculations. The catalyst [ $\mathrm{Cp} * \mathrm{RhCl} 2] 2$ and additive $\mathrm{Ag} 2 \mathrm{CO} 3$ play an important role in controlling the selectivity. By employing [ $\mathrm{Cp} * \mathrm{RhCl} 2] 2$ as catalyst and $\mathrm{Ag} 2 \mathrm{CO} 3$ as additive, the product is 1,6 -diketone, whereas the $\beta$ hydride elimination product could not be obtained. The product would become monoketone in the absence of $[\mathrm{Cp} * \mathrm{RhCl} 2] 2$. In addition, the combination of catalyst $\left[\mathrm{Cp}^{*} \mathrm{RhCl} 2\right] 2$ and additive AgOAc would also lead to monoketone. The observed selectivity could be attributed to the electronic effect.
\end{abstract}

Theoretical study on the Rh-catalyzed C-C activation of cyclopropanol to construct diketone or monoketone

Tao Liu ${ }^{1,2, *},+$, Ping Wang ${ }^{2,+}$, Hong Ren ${ }^{3}$

${ }^{1}$ Department of Chemistry and Chemical Engineering, Jining University, Qufu 273155, Shandong Province, People's Republic of China

${ }^{2}$ School of Chemistry and Chemical Engineering, Qufu Normal University, Qufu 273165, Shandong Province, People's Republic of China

${ }^{3}$ Information Management Center, Jining University, Qufu 273155, Shandong Province, People's Republic of China

Correspondent author email: liutao_2005@126.com

+ Tao Liu and Ping Wang have equally contributed to this work

ABSTRACT:The mechanisms of C-C activation of 1-Benzylcyclopropan-1-ol to produce 1,6-diketone have been investigated by density functional theory (DFT) calculations. The catalyst $\left[\mathrm{Cp}^{*} \mathrm{RhCl}_{2}\right]_{2}$ and additive $\mathrm{Ag}_{2} \mathrm{CO}_{3}$ play an important role in controlling the selectivity. By employing $\left[\mathrm{Cp}^{*} \mathrm{RhCl}_{2}\right]_{2}$ as catalyst and $\mathrm{Ag}_{2} \mathrm{CO}_{3}$ as additive, the product is 1,6-diketone, whereas the $\beta$-hydride elimination product could not be obtained. The product would become monoketone in the absence of $\left[\mathrm{Cp}^{*} \mathrm{RhCl}_{2}\right]_{2}$. In addition, the combination of catalyst $\left[\mathrm{Cp}^{*} \mathrm{RhCl}_{2}\right]_{2}$ and additive AgOAc would also lead to monoketone. The observed selectivity could be attributed to the electronic effect.

KEYWORDS: DFT; 1,6-diketone; selectivity; $\beta$-hydride elimination

\section{INTRODUCTION}


As one of the important carbon synthons to prepare pharmaceutically relevant and biologically active fiveand six-membered carbo- and heterocyclic compounds, ${ }^{[1-3]}$ 1,6-diketones and other acyclic long-chain diketones have attracted increasing attention in recent years. Although a lot of synthetic methods have been reported to yield 1,6-diketones, many of them were less efficiency and selectivity, and used non-readily obtainable substrates and synthetically harsh reaction conditions. ${ }^{[4,5]}$ Thus, a more general and efficient methodology to construct 1,6-diketones is highly desirable.

Transition-metal-catalyzed ring opening and cross-coupling reactions have been widely employed to synthesize 1,6-diketones from small carbocyclic rings. The intrinsic strain of small carbocyclic rings has been successfully exploited for the $\mathrm{C}-\mathrm{C}$ bond activation, ${ }^{[6]}$ by releasing of strain compensates to overcome the reachable thermodynamic barrier. Nevertheless, catalytic self-coupling of metal homoenolates using rhodiumhomoenolate derived from $\beta$-carbon elimination (C-C activation) of cyclopropanol is often restricted, ${ }^{[7-10]}$ due to the possible facile $\beta$-hydride elimination and isomerization pathways. ${ }^{[11]}$

Recently, Ravikumar et al reported a rhodium-catalyzed C-C activation of readily available cyclopropanols for one-step access to diverse 1,6-diketones at room temperature. ${ }^{[12]}$ The catalyst $\left[\mathrm{Cp}^{*} \mathrm{RhCl}_{2}\right]_{2}$ and additive $\mathrm{Ag}_{2} \mathrm{CO}_{3}$ play an important role in controlling the selectivity. As shown in Scheme 1, by employing $\left[\mathrm{Cp}^{*} \mathrm{RhCl}_{2}\right]_{2}$ as catalyst and $\mathrm{Ag}_{2} \mathrm{CO}_{3}$ as additive, 1-Benzylcyclopropan-1-ol ( $\mathbf{R}$ ) would furnish 1,6-diketone $\mathbf{P 1}$, whereas the $\beta$-hydride elimination product monoketone $\mathbf{P 1}$ ' could not be obtained (reaction $\mathrm{A}$ ). In contrast, the product would become monoketone $\mathbf{P} 2$ in the absence of $\left[\mathrm{Cp}^{*} \mathrm{RhCl}_{2}\right]_{2}$ (reaction $\mathrm{B}$ ). In reaction $\mathrm{C}$, the combination of catalyst $\left[\mathrm{Cp}^{*} \mathrm{RhCl}_{2}\right]_{2}$ and additive $\mathrm{AgOAc}$ would also lead to monoketone $\mathbf{P 2}$.

SCHEME 1 C-C activation of cyclopropanol reported by Ravikumar

et al

To account for the distinct regioselectivity, Ravikumar group postulated possible reaction mechanisms that are summarized in Scheme 2. $\left[\mathrm{Cp}^{*} \mathrm{RhCl}_{2}\right]_{2}$ firstly reacts with $\mathrm{Ag}_{2} \mathrm{CO}_{3}$ to generate active catalyst $\mathrm{Cp}^{*} \mathrm{RhCO}_{3}$ (cat ), which is followed by the ligand exchange with cyclopropanol $\mathbf{R}$ ' to afford alkoxide compound $\mathbf{I}$. FromI , there exist two possible pathways (path a or path $\mathrm{b}$ ). In path a, $\beta$-carbon elimination would take place to afford alkyl-rhodium homoenolate II . Then, with the participant of another molecule of cyclopropanol, the successive ligand exchange and $\beta$-carbon elimination occur to give dialkyl-rhodium speciesIV . In contrast, the ligand exchange with the second molecule of cyclopropanol prior to $\beta$-carbon elimination would yield species IV through compound II' (path b). Finally, reductive elimination from speciesIV leads to 1,6diketone $\mathbf{P}$. It should be noted that the $\beta$-hydride eliminated product $\mathbf{P}^{\prime}$ could not be obtained in this reaction. As shown in Scheme 2, in the absence of $\left[\mathrm{Cp}^{*} \mathrm{RhCl}_{2}\right]_{2}$, cyclopropanol would undergo the ringopening to give monoketone product catalyzed by $\mathrm{Ag}_{2} \mathrm{CO}_{3}$.

SCHEME 2 Possible reaction mechanisms proposed by Ravikumar's group

Although the plausible mechanistic pathway has been proposed by the Ravikumar group, some key issues still need to be addressed: (1) In this experiment, the role of the catalyst $\left[\mathrm{Cp} * \mathrm{RhCl}_{2}\right]_{2}$ and additive $\mathrm{Ag}_{2} \mathrm{CO}_{3}$ is still unclear; (2) It is unclear which steps determine the selectivity and what are the origins of that observation in this experiment; (3) The $\beta$-hydride eliminated product was not obtained in reaction A - it would be interesting to investigate the corresponding factors. To address these questions, a theoretical investigation of the detailed reaction mechanisms is needed. Herein, we report our detailed density functional theory (DFT) calculations on the reaction mechanisms, in order to gain insight into the interesting experimental observations and distinct selectivity. We expect that this work will help to understand the detailed reaction mechanisms and to design new related reactions.

\section{COMPUTATIONAL DETAILS}

All structures were optimized at the B3LYP ${ }^{[13-15]} /$ BSI level (BSI designates the basis set combination of LanL2DZ ${ }^{[16-18]}$ for Rh atom, and 6-31G(d,p) for main group elements) in the gas phase. Harmonic vibrational frequencies were also calculated at the same level of theory to identify all stationary points as minima (zero imaginary frequencies) or transition states (one imaginary frequency). Intrinsic coordinate reaction 
(IRC) ${ }^{[19-21]}$ calculations were carried out to examine the connectivity of a transition state with its backward and forward minima when necessary. The energetic results were then further refined by single-point calculations at the M06 $6^{[22,23]}$ /BSII level with solvation effects accounted for by the SMD ${ }^{[24-28]}$ solvent model using TFE as solvent according to the experimental conditions, where BSII denotes the basis set combination of $\mathrm{SDD}^{[29-31]}$ for Rh atom, and 6-311++G(d,p) for main group elements. Natural bond orbital (NBO) analyses were performed at the B3LYP/BSII level on selected systems with the NBO code included in Gaussian 09. ${ }^{[32]}$ In all of the figures that contain energy diagrams, calculated relative Gibbs free energies are presented. For reference, relative enthalpic energies are also given in parentheses. All the energies are given in $\mathrm{kcal} / \mathrm{mol}$. Unless otherwise stated, Gibbs free energies are used for the discussion of reaction mechanisms. All the calculations were performed with the Gaussian 09 software package. ${ }^{[32]}$

It should be noteworthy that the ideal gas-phase model intrinsically overestimates the entropic contributions, and thus the development of general schemes to correct the overestimation of entropic contributions is desired. Yu et al. ${ }^{[33,34]}$ have carried out a comparison between the entropies experimentally determined and those computed with the ideal gas model, and demonstrated that the latter could overestimate entropic contribution by $50-70 \%$ as compared to the former. In view of the overestimation of entropies with ideal gas-phase model, we applied a scaling factor of 0.5 to the gas phase entropic contributions as to correct the free energies for 2:1 and 1:2 transformations. Such a correction has been applied in other theoretical studies. $[35-44]$

\section{RESULTS AND DISCUSSION}

\subsection{Reaction A}

The free energy diagrams for the ligand exchange and $\beta$-carbon elimination in reaction $\mathrm{A}$ are calculated and shown in Figure 1. At the entrance of the reaction, $\mathbf{R}$ firstly coordinates with cat and $\mathrm{Ag}_{2} \mathrm{CO}_{3}$ to yield the intermediate $\mathbf{1}^{\mathbf{A}}$ by exoergic of $32.2 \mathrm{kcal} / \mathrm{mol}$. The inaccessible direct ring-opening of $\mathbf{R}$ with the assistance of $\mathrm{Ag}_{2} \mathrm{CO}_{3}$ is given in Figure $\mathrm{S} 1$ in Supporting Information (TS1-P2-1 $\mathbf{A}$ ). Then the ligand exchange takes place to generate an alkoxide intermediate $\mathbf{2}^{\mathbf{A}}$ via transition state $\mathbf{T S} \mathbf{1}^{\mathbf{A}}$ with a facile barrier of $0.2 \mathrm{kcal} / \mathrm{mol}$. In the following step, $\mathbf{2}^{\mathbf{A}}$ undergoes the $\beta$-carbon elimination to form an alkyl-rhodium homoenolate $\mathbf{3}^{\mathbf{A}}$ by overcoming the barrier of $20.5 \mathrm{kcal} / \mathrm{mol}\left(\mathbf{T S 2}^{\mathbf{A}}\right)$. The possible ring-opening processes from $\mathbf{2}^{\mathbf{A}}$ and $\mathbf{3}^{\mathbf{A}}$, respectively, caused by the protonation, were also calculated and precluded due to the high barriers (TS1-P2-2 ${ }^{\mathbf{A}}$ and TS1-P2-3 ${ }^{\mathbf{A}}$ in Figure S1 in Supporting Information).

FIGURE 1 Free energy diagrams for the ligand exchange and $\beta$-carbon elimination steps in reaction A. The relative free energies and relative enthalpic energies (in parentheses) are given in $\mathrm{kcal} / \mathrm{mol}$

FIGURE 2 Free energy diagrams for the second ligand exchange, second $\beta$-carbon elimination, and reductive elimination steps in reaction A. The relative free energies and relative enthalpic energies (in parentheses) are given in $\mathrm{kcal} / \mathrm{mol}$

With the coordination of another molecule of $\mathbf{R}, \mathbf{3}^{\mathbf{A}}$ transforms into intermediates4-cis ${ }^{\mathbf{A}}$ and4-tran ${ }^{\mathbf{A}}$, respectively, according to the relative position of two moieties of $\mathbf{R}$ (Figure 2). The subsequent ligand exchange then occurs to result into intermediates5-cis ${ }^{\mathbf{A}}$ and5-tran ${ }^{\mathbf{A}}$, respectively. The unfavorable $\beta$ hydride elimination from $\mathbf{3}^{\mathbf{A}}$ was excluded (TS3-P1'-1 $\mathbf{1}^{\mathbf{A}}$ in Figure S2 in Supporting Information). In the next step, another $\beta$-carbon elimination from $\mathbf{5}$ - $\mathbf{c i s}^{\mathbf{A}}$ and $\mathbf{5}$-tran ${ }^{\mathbf{A}}$ takes place to bring about intermediates 6-cis ${ }^{\mathbf{A}}$ and6-tran ${ }^{\mathbf{A}}$, through transition statesTS4-cis ${ }^{\mathbf{A}}$ andTS4-tran ${ }^{\mathbf{A}}$, respectively. The corresponding barriers are 19.0 and $22.1 \mathrm{kcal} / \mathrm{mol}$. Finally, the C-C reductive elimination occurs to produce the product-

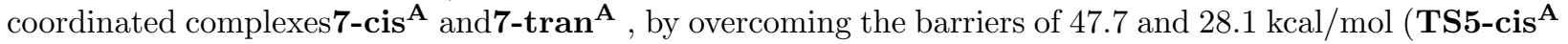
$\operatorname{andTS5-tran}^{\mathbf{A}}$ ), respectively. Another infeasible $\beta$-hydride elimination from 6-tran ${ }^{\mathbf{A}}$ was also considered and put into Figure S2 in Supporting Information (TS5-P1'-1 ${ }^{\mathbf{A}}$ ). Ravikumar et al also proposed an alternative pathway (path $\mathrm{b}$ as shown in Scheme 2), but this possibility is precluded due the high barrier (Figure S3 in Supporting Information).

As suggested in Figures 1 and 2, the rate-determining step for reaction $\mathrm{A}$ is the $\mathrm{C}-\mathrm{C}$ reductive elimination 
and the overall barrier is $28.1 \mathrm{kcal} / \mathrm{mol}$. The cis - or tran -selectivity is controlled by the competition between TS5-cis $^{\mathbf{A}}$ and TS5-tran ${ }^{\mathbf{A}}$. The lowerTS5- $\operatorname{tran}^{\mathbf{A}}$ indicates that thetran -product is the main product in reaction A. The steric effect could account for the regioselectivity. As shown the structures of TS5-cis $^{\mathbf{A}}$ andTS5-tran ${ }^{\mathbf{A}}$ in Figure 3, the strong repulsion of $\mathrm{Rh} \cdots \mathrm{C} 1$ interaction at $2.64 \AA$ in TS5$\mathbf{c i s}^{\mathbf{A}}$ destabilizes it and restricts the subsequent process.

FIGURE 3 The optimized structures of transition states of TS5-tran ${ }^{\mathbf{A}}$ andTS5-cis ${ }^{\mathbf{A}}$. The bond distances are given in $\AA$

FIGURE 4 NBO charges $(e)$ in the optimized structures of transition states TS3-P1-1 ${ }^{\text {A }}$ and

TS5-P1-1,A

In this reaction, the $\beta$-hydride elimination product monoketoneP1' was not found. The electronic effect could account for this selectivity. As indicated in the given NBO charges of corresponding $\beta$-hydride elimination transition states depicted in Figure 4, the strong attraction between $\mathrm{C}^{\beta}$ and $\mathrm{H}^{\beta}$, and repulsion between $\mathrm{Rh}$ and $\mathrm{H}^{\beta}$ restrain the $\beta$-hydride elimination jointly.

\subsection{Reaction B}

The free energy diagrams leading to $\mathbf{P 2}$ catalyzed by $\mathrm{Ag}_{2} \mathrm{CO}_{3}$ in reaction $\mathrm{B}$ are shown in Figure 3 . In the absence of cat, $\mathbf{R}$ would coordinate to $\mathrm{Ag}_{2} \mathrm{CO}_{3}$ firstly, ${ }^{[45]}$ which is followed by the ligand exchange to transform into intermediate $\mathbf{2}^{\mathbf{B}}$ with a barrier of $3.9 \mathrm{kcal} / \mathrm{mol}\left(\mathbf{T S 1} \mathbf{1}^{\mathbf{B}}\right)$. The subsequent ring-opening would furnish $\mathbf{P 2}$-coordinated complex $\mathbf{3}^{\mathbf{B}}$, requiring the barrier of $14.9 \mathrm{kcal} / \mathrm{mol}\left(\mathbf{T S 2}^{\mathbf{B}}\right)$. The infeasible ring-opening process is given in Figure $\mathrm{S} 4$ in Supporting Information. In contrast, from $\mathbf{2}^{\mathbf{B}}$, the $\beta$-carbon elimination could also take place to lead to $\mathbf{P 1}$ (red line in Figure 3), but the relative higher barrier of $\mathbf{T S 2 - P} \mathbf{1}^{\mathbf{B}}$ restricts this pathway. These calculated results are consistent with the experimentally observed selectivity.

FIGURE 5 Free energy diagrams leading to $\mathbf{P 1}$ andP2 in reaction A. The relative free energies and relative enthalpic energies (in parentheses) are given in $\mathrm{kcal} / \mathrm{mol}$

\subsection{Reaction $\mathrm{C}$}

As reported in this experiment, under the catalysis of cat and $\mathrm{AgOAc}, \mathbf{P 2}$ is the product. As presented in Figure 6, the ring-opening caused by the protonation of HOAc $\left(\mathbf{T S 1}-\mathbf{P 2} \mathbf{C}^{\mathbf{C}}\right)$ is much favorable than the $\beta$ carbon elimination pathway ( $\mathbf{T S 1 - P 1} \mathbf{C}^{\mathbf{C}}$ ), suggesting $\mathbf{P} 2$ is the product, in agreement with the experimental observation. The reversion on the selectivity, caused by different additives, could be attributed to the electronic effect. As the NBO charges shown in Figures 6 and 7, compared with $\mathrm{HCO}_{3}{ }^{-}$, the stronger acidity of HOAc could give the proton more easily and facilitate the ring-opening process.

FIGURE 6 The optimized structures of transition states of TS1-P1 ${ }^{\mathbf{C}}$ and TS1-P2 ${ }^{\mathbf{C}}$. The NBO charges are given in

$e$

FIGURE 7 NBO charges $(e)$ in the optimized structures of transition states TS1-P2-2 ${ }^{\mathbf{A}}$ and

TS1-P2-3 ${ }^{\mathrm{A}}$

\section{CONCLUSIONS}

In this study, DFT calculations were employed to study the mechanism of C-C activation of 1Benzylcyclopropan-1-ol to yield 1,6-diketone. The catalyst $\left[\mathrm{Cp} * \mathrm{RhCl}_{2}\right]_{2}$ and additive $\mathrm{Ag}_{2} \mathrm{CO}_{3}$ play an important role in controlling the selectivity. In reaction $\mathrm{A}$, the product is 1,6-diketone, whereas the $\beta$-hydride elimination product $\mathbf{P 1}$ ' could not be obtained. The electronic effect could account for the selectivity. In contrast, the product becomes monoketone in reaction $\mathrm{B}$ and $\mathrm{C}$. NBO charge calculation was performed to reveal the origin of the selectivity, which could be attributed to be the electronic effect.

\section{ACKNOWLEDGEMENTS}


This work was supported by the Natural Science Foundation of Shandong Province (No. ZR2019MB069).

\section{RERERENCES}

[1] M. Paradas, A. G. Campana, R. E. Estevez, L. Alvarez de Cienfuegos, T. Jimenez, R. Robles, J. M. Cuerva, J. E. Oltra, J. Org. Chem. 2009 , 74, 3616-3619.

[2] Y. Miyahara, Y. N. Ito, J. Org. Chem. 2014,79 , 6801-6807.

[3] S. Sarkar, A. Banerjee, W. Yao, E. V. Patterson, M. Y. Ngai,ACS Catal. 2019, 9 , 10358-10364.

[4] A. Saikia, A. Chetia, U. Bora, R. C. Boruah, Synlett.2003 , 10 , 1506-1508.

[5] X. Wang, M. Liu, L. Xu, Q. Wang, J. Chen, J. Ding, H. J. Wu, Org. Chem. 2013 , 78 , 5273-5281.

[6] G. Fumagalli, S. Stanton, J. F. Bower, Rev.2017, 117, 9404-9432.

[7] X. Zhou, S. Yu, L. Kong, X. Li, ACS Catal. 2016 ,6 , 647-651.

[8] X. K. Zhou, Z. S. Qi, S. J. Yu, L. H. Kong, Y. Li, W. F. Tian, X. W. Li, Adv. Synth. Catal. 2017, 359 , 1620-1625.

[9] R. Meng, S. Bi, Y. Y. Jiang, Y. Liu, J. Org. Chem.2019 , 84, 11150-11160.

[10] T. Avullala, P. Asgari, Y. Hua, A. Bokka, S. G. Ridlen, K. Yum, H. V. R. Dias, J. Jeon, ACS Catal. 2019, $9,402-408$.

[11] J. Kim, S. W. Park, M. H. Baik, S. Chang, J. Am. Chem. Soc. 2015 , 137, 13448-13451.

[12] B. V. Pati, A. Ghosh, P. C. Ravikumar, Org. Lett.2020, 22 , 2854-2860.

[13] S. J. Grimme, Comput. Chem. 2006 , $27,1787$.

[14] S. Grimme, J. Antony, S. Ehrlich, H. Krieg, J. Chem. Phys. 2010 , 132 , 154104.

[15] Y. M. Xing, L. Zhang, D. C. Fang, Organometallics.2015 , 34 , 770.

[16] X. Ji, P. Zhang, W. Wei, H. Zhang, B. Xia, J. Organomet. Chem. 2018, 862 , 40.

[17] Q. Wei, Y. Dai, C. Chen, L. Shi, Z. Si, Y. Wan, Q. Zuo, D. Han, Q. Duan, J. Mol. Struct. 2018 , 1171 , 786 .

[18] A. M. Mansour, O. R. Shehab, Inorg. Chem. Acta.2018 , 480 , 159.

[19] K. Yoshizawa, Y. Shiota, T. Yamabe, J. Chem. Phys. 1999, 111 , 538.

[20] S. Maeda, Y. Harabuchi, M. Takagi, K. Suzuki, T. Lchino, Y. Sumiya, K. Sugiyama, Y. Ono, J. Comput. Chem. $2018,39,233$.

[21] J. M. Burns, Org. Biomol. Chem. 2018 ,16 , 1828.

[22] F. Huang, J. Jiang, M. Wen, Z. Wang, J. Theor. Comput. Chem. 2014, 13 , 1350074.

[23] C. A. Bayse, Inorg. Chem. 2006 , 45, 2199.

[24] D. G. Fedorov, Chem. Phys. Lett. 2018 ,702, 111.

[25] K. Aidas, J. Comput. Chem. 2015 , 36 , 2158.

[26] J. J. Guerard, J. S. Arey, J. Chem. Theor. Comput.2013, 9 , 5046.

[27] L. Castro, E. Kirillov, O. Miserque, A. Welle, L. Haspeslagh, J. F. Carpentier, L. Maron, ACS Catal. $2015,5,416$.

[28] K. Jana, B. Ganguly, J. Phys. Chem. A. 2014,118, 9753. 
[29] D. Andrae, U. Haeussermann, M. Dolg, H. Stoll, H. Preuss, Theor. Chim. Acta. 1990 , 77 , 123.

[30] G. V. Barnett, V. I. Razinkov, B. A. Kerwin, T. M. Laue, A. H. Woodka, P. D. Butler, T. Perevozchikova, C. J. Roerts, J. Phys. Chem. B. $2015,119,5793$.

[31] Y. Liu, C. Sun, S. Zhang, Theor. Chem. Acc.2013, $132,1$.

[32] M. J. Frisch, G. W. Trucks, H. B. Schlegel, G. E. Scuseria, M. A. Robb, J. R. Cheeseman, G. Scalmani, V. Barone, B. Mennucci, G. A. Petersson,H. Nakatsuji, M. Caricato, X. Li, H.P . Hratchian, A. F. Izmaylov, J. Bloino, G. Zheng, J. L. Sonnenberg, M. Hada, M. Ehara, K. Toyota, R. Fukuda, J. Hasegawa, M. Ishida, T. Nakajima, Y. Honda, O. Kitao, H. Nakai, T. Vreven, J. A. Montgomery Jr., J. E. Peralta, F. Ogliaro, M. Bearpark, J. J. Heyd, E. Brothers, K. N. Kudin, V. N. Staroverov, R. Kobayashi, J. Normand, K. Raghavachari, A. Rendell, J. C. Burant, S. S. Iyengar, J. Tomasi, M. Cossi, N. Rega, N. J. Millam, M. Klene, J. E. Knox, J. B. Cross, V. Bakken, C. Adamo, J. Jaramillo, R. Gomperts, R. E. Stratmann, O. Yazyev, A. J. Austin, R. Cammi, C. Pomelli, J. W. Ochterski, R. L. Martin, K. Morokuma, V. G. Zakrzewski, G. A. Voth, P. Salvador, J. J. Dannenberg, S. Dapprich, A. D. Daniels, O. Farkas, J. B. Foresman, J. V. Ortiz, J. Cioslowski, D. J. Fox, Gaussian 09, Revision D. 01, Gaussian Inc. Wallingford CT.2009 .

[33] Z. X. Yu, K. N. Houk, J. Am. Chem. Soc . 2003 ,125, 13825.

[34] Y. Liang, Z. X. Yu, Chem. Eur. J. $2008,14,4361$.

[35] L. L. Zhao, M. W. Wen, Z. X. Wang, Eur. J. Org. Chem.2012, $2012,3587$.

[36] T. Liu, S. M. Han, L. L. Han, L. Wang, X. Y. Cui, C. Y. Du, S. W. Bi, Org. Biomol. Chem. 2015 , 13 , 3654-3661.

[37] T. Liu, S. W. Bi, Organometallics . 2016 ,35, 1114-1124.

[38] L. L. Han, Y. P. Li, T. Liu, Dalton Trans.2018 , 47 , 150-158

[39] K. Lv, Y. Y. Jiang, L. L. Han, T. Liu, S. W. Bi, Mol. Catal. 2019 , 462 , 77-84

[40] D. H. Wertz, J. Am. Chem. Soc. 2002 ,102 , 5316-5322.

[41] M. H. Abraham, J. Am. Chem. Soc . $1981,103,6742-6744$.

[42] J. Hermans, L. Wang, J. Am. Chem. Soc . 1997,119 , 2707.

[43] D. V. Deubel, J. Am. Chem. Soc. 2008 ,130, 665-675.

[44] R. E. Plata, D. A. Singleton, J. Am. Chem. Soc.2015 , 137, 3811-3826.

[45] K. L. Bay, Y. F. Yang, K. N. Houk. J. Organomet. Chem.2018, 864, 19-25. 